REVIEW

\title{
Tacrolimus ointment in the management of atopic dermatitis
}

\author{
Antonello Baldo \\ Mariana Cafiero \\ Paola Di Caterino \\ Luisa Di Costanzo
}

Department of Dermatology, University of Naples Federico II, Naples, Italy
Correspondence:Antonello Baldo Dipartimento di Patologia Sistematica Sezione di Dermatologia clinica, allergologica e venereologica - Università di Napoli Federico II - via S Pansini,

5 CAP 80 I3I Napoli, Italy

Tel +39817462365

Fax +398I 7462442

Email baldo@unina.it

\begin{abstract}
Atopic dermatitis (AD) is a chronic, relapsing, highly pruritic inflammatory skin disease. $\mathrm{AD}$ long-term treatment is usually required to control and prevent flares, and patients need a treatment that is safe and efficacious when applied continuously or intermittently over a prolonged period of time. The treatment options should be chosen according to age, clinical features and severity of the disease in every single patient. For the treatment of a chronic disease like $\mathrm{AD}$, sustained tolerability and efficacy of the applied medications are essential. A topical immunomodulator, tacrolimus ointment, provides an alternative to topical corticosteroids without the associated adverse events. Tacrolimus is a macrolide lactone with unique immunomodulatory properties and strong anti-inflammatory activities and can be used without increasing the risk of infection or other non-application site adverse events, and without loss of effectiveness, in patients with $\mathrm{AD}$.
\end{abstract}

Keywords: atopic dermatitis, tacrolimus, safety

\section{Atopic dermatitis: general aspects}

Atopic dermatitis (AD) is a chronic, relapsing, highly pruritic inflammatory skin disease that is particularly prevalent in the pediatric population, as $60 \%$ of the cases are diagnosed under the age of 1 year. ${ }^{1}$

It is the most common chronic disease of childhood and its incidence has been increasing during the recent decades in Western countries. The prevalence of AD is $10 \%$ to $20 \%$ in children and $1 \%$ to $3 \%$ in adults in temperate developed countries. ${ }^{2}$ $\mathrm{AD}$ has a chronic or chronically relapsing course with remissions and exacerbations of variable length. Typical clinical features include multiple lesions with erythema, excoriation, erosions accompanied by a serous exudate, accentuated skin markings (lichenification), fibrotic papules, severely dry skin, and a susceptibility to cutaneous infections. ${ }^{3}$ The main symptom is intense itching and excessive scratching can cause further damage such as excoriation, erosions and infections. ${ }^{4}$ The lesions have a typical age-dependent distribution pattern. In infants, nummular or seborrhoeic type eczema occurs on the cheeks, chin and trunk. In 1- to 4-year-old children, affected areas include extensor and sometimes flexural sides of the extremities, the hands, face, neck and perioral area. In 4- to 16-year-old children, flexural eczema predominates, with face, hands, feet and gluteal area affected. In adults, eczema most often occurs on the face, neck, upper body and extremities. ${ }^{5} \mathrm{AD}$ is a clinical diagnosis. Hanifin and Rajka were the first to develop a diagnosis of this disease based on defined criteria, ${ }^{6}$ as described in Table 1 . The histopathology is quite typical for any type of eczema with a superficial perivascular inflammatory infiltrate consisting mainly of T lymphocytes. ${ }^{7}$ The etiology of $\mathrm{AD}$ is unknown, but it is thought that a genetic presposition exists with symptoms being triggered by various external and psychological factors. ${ }^{8}$

The genetic predisposition is strong. Its parental inheritance ${ }^{9}$ is complex and includes multiple gene interactions and environmental influences. AD, asthma 
Table I The Hanifin and Rajka criteria: shortened list

\begin{tabular}{ll}
\hline Major criteria & Pruritus \\
& Early age of onset \\
& Typical morphology and distribution; \\
& flexural lichenification and linearity \\
& in adults; facial and extensor involve- \\
& ment during infancy and childhood \\
& Chronic or chronically relapsing \\
& dermatitis \\
& Personal or family history of atopy \\
& (asthma, allergic rhinoconjunctivitis, \\
& atopic dermatitis) \\
& Xerosis \\
Ichthyosis & Palmar hyperlinearity \\
Minor or less & Keratosis pilaris \\
Immediate skin response & Hand/foot dermatitis \\
Cheilitis & Nipple eczema \\
Susceptibility to cutaneous infections \\
(especially Staphylococcus aureus and \\
herpes simplex) \\
Perifollicular accentuation \\
\\
cria
\end{tabular}

and elevated serum IgE have been linked to almost every chromosome, but no single gene can be implicated as the gene for the development of the skin disease. ${ }^{10}$

This hyper-IgE condition leads to a group of atopy-related diseases in many AD patients, such as asthma and allergic rhinitis, bronchial hyper-responsiveness and eosinophilic airway inflammation, atopic blepharoconjunctivitis. ${ }^{8-9}$

Pathophysiology of AD is characterized by dysregulated immune responses that consist of an increased systemic Th2 response and a combination of Th2 and Th1 responses in the skin lesions. ${ }^{11}$ Recent studies highlight the role of antigenspecific effector T-lymphocytes and down-regulatory CD4+ T-cells (Treg). These cells are responsible for the cutaneous inflammatory response through the production of inflammatory cytokines and the destruction of keratinocytes by apoptosis. ${ }^{12}$

Moreover in AD patients skin barrier function is deeply altered. Peptides with a molecular mass over 500 Da do not penetrate healthy normal skin, whereas in AD, environmental allergens of up to $20 \mathrm{kDa}$ may penetrate the skin. This makes the skin susceptible to environmental factors such as detergents, irritants, allergens, microbial toxins, and physical or psychological stress. ${ }^{13}$ Defects of epidermal differentiation such as altered filaggrin expression weaken the epidermal barrier and predispose patients with AD to epicutaneous allergic sensitization as well as to physical, microbial and irritant skin damage. This barrier damage activates keratinocytes to produce inflammatory cytokines and starts the inflammatory cycle leading to T-cell activation, IgE-production and clinical AD. ${ }^{14}$

About $70 \%$ to $80 \%$ of patients with $\mathrm{AD}$ are considered to have classical, ie, IgE-associated or allergic, AD because they show elevated serum-IgE levels or positive skin prick test results for aeroallergens or food allergens, whereas the remaining 20\% to 30\% never show this kind of IgE-mediated sensitization and are considered to have non-IgE-associated or non-allergic AD. ${ }^{15}$

IgE-mediated sensitization may not yet be evident in infants or young children but it develops with increasing age. As the skin barrier function in $\mathrm{AD}$ is weakened, and the skin is deficient in antimicrobial peptides such as defensins and cathelisins, various microbes are able to colonize the skin and cause secondary infections. The clinically relevant microbes in AD are Staphylococcus aureus, herpes simplex virus (HSV), and Malassezia (formerly known as Pityrosporum) yeast species. ${ }^{13}$

AD can significantly affect the child's quality of life as patients are often distressed by their appearance, have low self-esteem and sometimes cannot enjoy normal routine activities and social interactions. ${ }^{4}$

\section{Treatment options in AD}

$\mathrm{AD}$ tends to be a chronic disease with a relapsing course so that long-term treatment is usually required to control and prevent flares. Patients need a treatment that is safe and efficacious when applied continuously or intermittently over a prolonged period of time. The treatment options should be chosen according to age, clinical features and severity of the disease in every single patient.

Topical glucocorticosteroids (corticosteroids) have been the mainstay of AD treatment for the past few decades. They relieve the symptoms and inflammation of $\mathrm{AD}$ quickly but are officially indicated only for short-term use, usually for only 1 to 3 weeks. In long-term use of the compounds cutaneous side-effects are common, and include skin atrophy, bruising, telangiectasies, striae, steroid acne, hypertrichosis, tachyphylaxis, increased treatment tolerance (steroid resistance), and worsening of underlying secondary infections. Topical corticosteroids for treatment of eyelid and facial eczema may increase intraocular pressure and induce glaucoma and cataracts. $^{16}$

Antihistamines are widely used for patients with AD, especially if allergic rhinoconjunctivitis and allergic asthma are co-existent. First-generation compounds such as hydroxyzine are useful for nocturnal pruritus due to their sedative effect. They do not seem to work on pruritus itself because, 
unlike in urticaria, histamine is not considered to be a major pruritogen in $\mathrm{AD}{ }^{16,17}$

Commonly it is possible to manage AD with topical treatments or in association with antihistamines, but, on the other hand, severe $\mathrm{AD}$ that does not respond adequately to topical treatment often requires the addition of systemic long-term immunomodulator treatment. ${ }^{14}$

Systemic glucocorticosteroids such as prednisone, prednisolone and methylprednisolone often serve as rescue therapy in severe AD exacerbations. They relieve itch and inflammation quickly, but the risk for AD relapse soon after cessation of treatment is high. In addition to having the same side-effects as topical corticosteroids, they may cause arterial hypertension, electrolyte imbalance, impaired glucose metabolism, Cushing's syndrome, and osteoporosis, especially in long-term treatment. ${ }^{16-18}$

Cyclosporine (cyclosporine A) is a non-myelosuppressive immunosuppressant, extensively studied in $\mathrm{AD}$, and has shown good efficacy in adults and children. It acts by downregulating and inhibiting the cytokine production of Th2 cells. Treatment of $\mathrm{AD}$ with cyclosporine requires a regular follow-up by a dermatologist owing to its possible adverse effects: arterial hypertension, nephrotoxicity, immunosuppression and oncogenetic potential. The usual initial dose is 2.0 to $5.0 \mathrm{mg} / \mathrm{kg}$, which should be tapered down to the lowest effective dose..$^{19,20}$

Azathioprine is an old compound used for similar indications as for cyclosporine. Adverse effects include bone marrow suppression and increased oncogenic risk. At present, the long-term effects of azathioprine in AD are unknown. ${ }^{20}$

Methotrexate is another old drug compound used similarly to azathioprine. Its main adverse effects include liver toxicity, anemia, thrombopenia, gastrointestinal dysfunction and pneumonitis. ${ }^{20}$ Other newer treatment modalities tried for severe treatment-resistant AD include mycophenolate mofetil, interferon gamma (IFN- $\gamma$ ), intravenous immunoglobulin (IVIG) and the new TNF- $\alpha$ inhibitors or "biologic" treatments designed for rheumatoid arthritis and psoriasis $^{20}$ (Table 2).

However, all these therapeutical options will diminish but not eliminate the need for topical treatments, so that they are considered as secondary treatments of $\mathrm{AD}$, combined with topical corticosteroids when these are not sufficient to control the disease. They may diminish the need for topical corticosteroids but do not replace them. ${ }^{21}$

Several types of ultraviolet (UV) light therapy can be associated with topical treatment: UVB, narrow-band UVB (311-313 nm), UVA (320-400 nm) and PUVA (UVA usually with topical photosensitizing psoralens). Adverse effects include skin erythema, which is less with UVB treatment, skin burning and risk for skin malignancies with cumulative UV dose. ${ }^{22}$

For the treatment of a chronic disease like AD, sustained tolerability and efficacy of the applied medications are essential. A topical immunomodulator, tacrolimus ointment, provides an alternative to topical corticosteroids without the associated adverse events.

\section{Mechanism of action of tacrolimus}

Tacrolimus ointment is a topical calcineurin inhibitor (TCI) and was the first of this class of topical preparations to be developed particularly for the treatment of $\mathrm{AD} .^{23}$

Tacrolimus is a macrolide lactone with unique immunomodulatory properties and was originally isolated in Japan in 1980 from the fungus-like bacterium Streptomyces tsukubaensis. It was first approved for the treatment of AD in Japan in 1999, with approvals following for the USA in 2000 and for The European Union in 2002. ${ }^{24-26}$

Tacrolimus is absorbed passively into skin, particularly in affected skin, and reduces skin inflammation and pruritus in $\mathrm{AD}$, blocking $\mathrm{T}$-cells activation by binding to the cytosolic immunophilin receptor (macrophilin-12) to form a complex that inhibits the activity of the enzyme calcineurin. Calcineurin normally dephosphorylates a cytosolic transcription factor, the nuclear factor of activated T-cell protein (NF-ATp), allowing it to travel to the nucleus, where it initiates the activation of a variety of genes involved in T-cell activation. ${ }^{25,27}$

Because this transcription factor is essential for the production of IL-2 and other cytokines (INF-gamma, IL-3, IL-4, IL-5), prevention of its translocation effectively inhibits Th1-cell and Th2-cell activation. Calcineurin inhibition can also decrease production of both the proinflammatory cytokines, tumor necrosis factor and granulocyte-macrophage colony-stimulating factor, necessary for the maturation of dendritic cells. ${ }^{28-31}$

Tacrolimus effects on the immune system (including antigen-presenting cells [APC] T-lymphocytes, mast cells and keratinocytes) are well studied. In AD pathogenesis, APC are involved: CD1a+ epidermal APC are more represented in untreated lesions of the disease, but it has been demonstrated that treatment with topical tacrolimus reduces CD1a+ expression..$^{25,32,33}$ Several in vivo animal studies confirm that tacrolimus can inhibit the effective phase of contact hypersensitivity (in mice) and partially the sensitization phase of contact hypersensitivity.

Moreover further studies have demonstrated that in vivo keratinocyte apoptosis induced by activated T-cells is significantly reduced after successful topical treatment with tacrolimus. This effect is mediated by 2 major mechanisms 
directed on T-cells or keratinocytes: direct T-cell inhibition and Fas-mediated keratinocyte apoptosis inhibition of eczematous lesions. ${ }^{34}$

Therefore topical tacrolimus has strong anti-inflammatory activities and a pronounced immunosuppressant potential..$^{25,35-37}$

\section{Tacrolimus ointment - clinical studies}

\section{Efficacy - short-term studies}

Efficacy of tacrolimus has been demonstrated in many short-term studies.

In several vehicle-controlled short-term studies, tacrolimus ointment, both $0.03 \%$ and $0.1 \%$, was significantly more effective than the vehicle in treating adults and children affected by AD, with no significant differences between the two different concentrations. ${ }^{38}$ Tacrolimus $0.03 \%$ and $0.1 \%$ ointments have been compared with topical steroids. In a randomized, doubleblind study in 2- to 15-year-old children affected by moderate to severe $\mathrm{AD}$, both concentrations showed a significantly greater improvement than $1 \%$ hydrocortisone acetate. ${ }^{38,39}$ In adult patients with moderate to severe $\mathrm{AD}$, tacrolimus $0.1 \%$ was as effective as hydrocortisone-17-butyrate, and both were superior to the $0.03 \%$ ointment. ${ }^{40}$ In a 3 -week study in a pediatric population, tacrolimus $0.03 \%$ ointment applied once or twice daily had greater efficacy than hydrocortisone $1 \%$ acetate applied twice daily, even though, especially in patients with more severe baseline disease, double daily application of tacrolimus was more effective than single application. ${ }^{41}$ Even compared with cyclosporine, tacrolimus has been demonstrated to be superior: a 6-week study showed that efficacy of $0.1 \%$ ointment was better than that of oral cyclosporine $3 \mathrm{mg} / \mathrm{kg}$. ${ }^{42}$

\section{Efficacy - long-term studies}

Efficacy of tacrolimus ointment has been assessed in several thousand adult and pediatric patients in long-term, openlabel, non-comparative, multicenter studies lasting for 12 to 48 months, in Europe and the US. In both adult and pediatric populations with moderate to severe $\mathrm{AD}, 0.1 \%$ tacrolimus ointment has showed rapid and protracted improvement

Table 2 Principal systemic treatment for atopic dermatitis

\begin{tabular}{|c|c|c|}
\hline Treatment & Mechanism of action on AD & Adverse effects \\
\hline Corticosteroids & $\begin{array}{l}\text { Reduction of number and activity of lymphocites } \\
\text { Reduction of inflammatory cytokines (IL-I } 2 \text { and } \\
\text { INF- } \gamma \text { ) } \\
\text { Reduction of cyclooxygenase, platelet activating } \\
\text { factor } \\
\text { Vasoconstriction and reduction of small vessels } \\
\text { permeability }\end{array}$ & $\begin{array}{l}\text { Systemic effects: hypothalamic-pituitary-adrenal axis } \\
\text { suppression, reduced linear growth in children, and } \\
\text { bone density changes in adults } \\
\text { Local effects: skin atrophy, bruising, telangiectasies, } \\
\text { striae, steroid acne, hypertrichosis, tachyphylaxis, } \\
\text { steroid resistance, worsening of underlying } \\
\text { secondary infections }\end{array}$ \\
\hline UVB-treatment & $\begin{array}{l}\text { Suppression of Th2 chemokine production sug- } \\
\text { gests that UVB exposure to the skin suppresses } \\
\text { infiltration of Th2 cells to the epidermis }\end{array}$ & $\begin{array}{l}\text { Skin erythema, skin burning, risk for skin } \\
\text { malignancies }\end{array}$ \\
\hline Cyclosporine & $\begin{array}{l}\text { Inhibition of II-2 production by blocking the } \\
\text { function of the enzyme calcineurin }(\mathrm{CaN})\end{array}$ & $\begin{array}{l}\text { Arterial hypertension, nephrotoxicity, } \\
\text { and immunosuppression }\end{array}$ \\
\hline Methotrexate & $\begin{array}{l}\text { Inhibition of synthesis of purines and pirimidines } \\
\text { required for cellular proliferation of lymphocytes }\end{array}$ & $\begin{array}{l}\text { Anemia, thrombopenia, gastrointestinal dysfunction, } \\
\text { and pneumonitis }\end{array}$ \\
\hline Antihistamines & $\begin{array}{l}\text { Inhibition of peripherical histamines receptors } \\
\text { with reduction of vasodilatation and itching, } \\
\text { inhibition of central histamines receptors with } \\
\text { sedative effect, local anesthetic effect }\end{array}$ & Excessive sedation \\
\hline Azathioprine & $\begin{array}{l}\text { Inhibition of purine synthesis with consequent } \\
\text { stop in synthesis of DNA, RNA, and proteins; it } \\
\text { may also interfere with cellular metabolism and } \\
\text { inhibit mitosis the proliferation of cells, especially } \\
\text { leukocytes }\end{array}$ & $\begin{array}{l}\text { Bone marrow suppression and oncogenic potential, } \\
\text { gastrointestinal symptoms. Leukopenia or infection } \\
\text { fever or chills, cough or hoarseness, lower back or } \\
\text { side pain, painful or difficult urination, tiredness or } \\
\text { weakness }\end{array}$ \\
\hline Mycophenolate mofetil & $\begin{array}{l}\text { Inhibition of inosine monophosphate } \\
\text { dehydrogenase (IMPDH), with following de novo } \\
\text { synthesis pathway of guanosine nucleotides } \\
\text { (on which T and B lymphocytes are critically } \\
\text { dependent for their proliferation) }\end{array}$ & $\begin{array}{l}\text { Bone marrow suppression, peripheral edema, } \\
\text { arrhythmia, artralgia }\end{array}$ \\
\hline TNF- $\alpha$ inhibitors & $\begin{array}{l}\text { Through inhibition of TNF- } \alpha \text {, which has a great } \\
\text { inflammatory activity, reduction in epidermal } \\
\text { hyperplasia neoangiogenesis and itching }\end{array}$ & $\begin{array}{l}\text { Increased risk of infection, especially reactivation of } \\
\text { tuberculosis; increased risk of lymphoproliferative } \\
\text { diseases, worsening of heart failure; local reactions }\end{array}$ \\
\hline
\end{tabular}


in efficacy parameters ${ }^{3,43,44}$ Children treated with $0.03 \%$ ointment intermittently for 12 to 29 months and with $0.1 \%$ ointment periodically if the $0.03 \%$ was insufficient, showed substantial improvement in efficacy parameters, including pruritus within 2 weeks, and maintained the result throughout the study. ${ }^{45}$

A multicenter, randomized, double-blind, controlled study of 6 months compared tacrolimus ointment $0.1 \%$ on the trunk and extremities with hydrocortisone-17-butyrate and on the face and neck with $1 \%$ hydrocortisone acetate in an adult population with moderate to severe AD. Tacrolimus achieved greater improvement in all efficacy parameters, and a higher percentage of the patients showed at least a $60 \%$ response $(72.6 \%$ vs $52.3 \%, \mathrm{p}<0.001){ }^{46}$

\section{Tacrolimus and safety}

Safety of tacrolimus ointment has been demonstrated in short- and especially long-term studies, as it has been demonstrated that systemic absorption of tacrolimus from topical application is largely minimal. Topical treatment can lead to blood concentrations of a maximum of approximately $3 \%$ of those of transplant patients using systemic tacrolimus, with no signs of accumulation of tacrolimus after repeated application. ${ }^{23,47,48}$

The most common adverse events of application of tacrolimus ointment ( $\sim 60 \%$ of patients) are limited to the site of application, such as pruritus and "skin burning", with burning sensation, pain, stinging, erythema, soreness and flushes especially after alcohol ingestion. ${ }^{49,50}$ Most episodes of skin burning last less than 10 minutes and most episodes of pruritus last less than 1 hour. The prevalence of application site adverse events, in particular skin burning and pruritus, more frequent in adults than in children, is highest during the first few days of treatment and then declines. For most patients who experienced an application site adverse event, the severity of the worst episode is mild or moderate. ${ }^{49}$

No case of skin atrophy has been reported and, moreover, long-term treatment with tacrolimus ointment has been associated with improvements in collagen synthesis and skin thickness. ${ }^{24,50}$

Sun avoidance is recommended during tacrolimus therapy ${ }^{23}$ which led to black box warnings in the US on increased cancer risk from topical tacrolimus, despite the fact that, to date, the development of skin cancer as result of tacrolimus ointment treatment has not been reported. ${ }^{51}$

However, a recent large case-control study with a cohort of almost 290,000 patients receiving different $\mathrm{AD}$ treatments showed that the main factor associated with increased lymphoma risk is $\mathrm{AD}$ severity, whereas there was no increased risk of lymphoma in patients treated with topical calcineurin inhibitors. ${ }^{51}$

One of the most discussed adverse effects of topical tacrolimus was the increase of infections but most of these are considered mild or moderate in severity and were not confirmed by the study investigators to be related to the use of tacrolimus ointment. ${ }^{49}$ Nevertheless there is no evidence of an increase in the risk of cutaneous infections with long-term use of tacrolimus ointment, and the incidence of cutaneous infections in the long-term studies is comparable with that observed with 12-week application. ${ }^{52}$

No clinically meaningful changes in mean or median values for hematology, indicators of hepatic or renal function, serum electrolytes, blood glucose and serum IgE have been observed. ${ }^{49}$

According to a recent systemic review on topical treatment of $\mathrm{AD}$, significant local or systemic adverse events are mainly associated with use of topical corticosteroids. ${ }^{53}$

These findings suggest that tacrolimus ointment may be a better choice for long-term treatment to control and prevent $\mathrm{AD}$ flares in all patients, including children. ${ }^{30}$

\section{Topical tacrolimus in practice}

$\mathrm{AD}$ is a disease resulting from the interaction of genetic, environmental and immunological factors and presents many clinical aspects. ${ }^{30}$ Therefore, patients suffering from AD require individual management.

Many studies have demonstrated that tacrolimus ointment is effective for the treatment of AD. ${ }^{54,55}$ Tacrolimus ointment is suitable for the short and intermittent long-term treatment of moderate to severe $\mathrm{AD}$ in patients over 24 months old who are not adequately responsive or are intolerant to conventional therapies, such as topical corticosteroids..$^{30,50}$ A significant improvement of the disease is notable within 1 week of starting tacrolimus therapy. For adult and pediatric patients, the ointment should be applied at the first sign of dry skin or pruritus. In adult patients the treatment should be initiated with tacrolimus $0.1 \%$ twice daily for 3 or 4 weeks; later on the concentration and the dosage can be reduced. ${ }^{30}$

In pediatric patients, it is advised to begin the treatment with tacrolimus $0.03 \%$ twice daily for 3 or 4 weeks, followed by once-daily application until the lesions improve. ${ }^{30}$

Potent topical corticosteroids are used reactively to treat AD flares. Unlike potent corticosteroids, tacrolimus ointment can be used to reduce the incidence of disease flares and also the severity of flares without the risk of corticosteroid-related adverse events. ${ }^{16,31,53}$ 
Furthermore, in contrast to topical corticosteroids, tachyphylaxis or rebound are not observed, even in longterm tacrolimus treatment. ${ }^{56}$ Moreover, tacrolimus ointment application makes the therapy of AD easy.

It is effective as monotherapy and its safety profile enables its use on all affected areas of the body (including face, neck and fold sites) for as long as necessary, without the need for concomitant corticosteroid therapy. ${ }^{57}$ This is one of the most important differences between tacrolimus and topical corticosteroid regimens routinely used. In fact, topical steroids therapy includes a less potent preparation on sensitive skin areas and a more potent preparation on other affected areas for a short time to diminish adverse-related effects. ${ }^{40,58,59}$

Although tacrolimus has potent immunosuppressive ability, it does not seem to increase Staphylococcus aureus colonization, probably because of its healing effects on the skin, which can reduce the ability of adhesion molecules necessary for staphylococcal colonization. ${ }^{60,61}$

No studies have reported significant enhancement of viral or bacterial infections in patients treated with tacrolimus ointment. $^{43,62}$

It is important to advise patients using tacrolimus ointment to avoid a solarium, to minimize exposure to sunlight, and to use sunscreen, even though it is not a photo-sensitizer. ${ }^{23}$ Moreover the risk of photo-carcinogenicity with topical tacrolimus is small in clinical practice. ${ }^{30,63-65}$

In conclusion, $0.03 \%$ and $0.1 \%$ tacrolimus ointment can be used daily for periods of up to 1 year for AD treatment in patients, including padiatric patients, without increasing the risk of infection or other non-application site adverse events, and without loss of effectiveness. ${ }^{47,57}$

\section{Disclosures}

The authors declare no conflicts of interest or sources of funding.

\section{References}

1. Schultz-Larsen F, Diepgen T, Svensonn A. The occurrence of atopic dermatitis in north Europe: an international questionnaire study. $J \mathrm{Am}$ Acad Dermatol. 1996;34:760-764.

2. Kay J, Gawkrodger DJ, Mortimer MJ, Jaron AG. The prevalence of childhood atopic eczema in general population. J Am Acad Dermatol. 1994;30:35-39.

3. Reitamo S, Wollenberg A. Safety and efficacy of 1 year of tacrolimus ointment monotherapy in adults with atopic dermatitis. Arch Dermatol. 2000;36:999-1006.

4. Leung DYM. Atopic dermatitis: new insights and opportunities for therapeutic intervention. J Allergy Clin Immunol. 2000;105:860-876.

5. Bohme M, Svensson A, Kull I, Nordvall SL, et al. Clinical features of atopic dermatitis at two years of age. Acta Derm Venereol. 2001; 81:193-197.

6. Hanifin JM, Rajka G. Diagnostic features of atopic eczema. Acta Derm Venereol. 1980;Supp1 92:44-47.
7. Akdis C, Akdis M, Bieber T. Diagnosis and treatment of atopic dermatitis in children and adults: European Academy of Allergology and Clinical Immunology/American Academy of Allergy, Asthma and Immunology/Practall Consensus Report. Allergy. 2006;61:969-987.

8. Bernard LA, Eichfield LF. Topical immunomodulators for atopic dermatitis. Curr Opinion Pediatr. 2002;14:414-418.

9. Dold S, Wjst M, von Mutius E. Genetic risk for asthma, allergic rhinitis, and atopic dermatitis. Arch Dis Child. 1992;67:1018-1022.

10. Cork MJ, Robinson DA, Vasilopoulos Y, et al. New perspectives in epidermal barrier dysfunction in atopic dermatitis: Gene-environment interactions. J Allergy Clin Immunol. 2006;118:3-21.

11. Ong PY, Leung DY. Immune dysregulation in atopic dermatitis. Curr Allergy Asthma Rep. 2006;6(5):384-389.

12. Hennino A, Vocanson M, Berard F, et al. Epidemiology and pathophysiology of eczemas. Rev Prat. 2006;15:56(3):249-257.

13. Bos JD, Meinardi MM. The 500 Dalton rule for the skin penetration of chemical compounds and drugs. Exp Dermatol. 2000;9:165-169.

14. Vickery BP. Skin barrier function in atopic dermatitis. Curr Opin Pediatr. 2007;19:89-93.

15. Wütrich B, Schmid-Grendelmeier P. Definition and diagnosis of intrinsic versus extrinsic atopic dermatitis. In: Bieber T, Leung DYM, editors. Atopic dermatitis. 1st ed. New York: Marcel Dekker Inc; 2002. p. $1-20$.

16. Hoare C, Li Wan Po A, Williams H. Systematic review of treatments of atopic dermatitis. Health Technol Assess. 2000;4(37):1-191.

17. Wahlgren CF. Itch and atopic dermatitis: an overview. J Dermatol. 1999;26(11):770-779.

18. Aberer W, Wolff K. Systemic Pharmacotherapy. In: Bieber T, Leung DYM editors. Atopic dermatitis. Marcel Dekker Inc., New York, Basel; 2002. p. 595-602.

19. Yajima Y, Sueki H, Oguro T, Yoshida T, Iijima M. Effects of oral administration of ciclosporin A on skin carcinogenesis: a study using the two-stage carcinogenesis protocol in mice Clin Exp Dermatol. 2008;33(4):478-483.

20. Schmitt J, Schäkel K, Schmitt N, et al. Systemic treatment of severe atopic dermatitis: A systematic review. Acta Derm Venereol. 2007;87:100-111.

21. Smith JG, Wehr RF, Chalker DK. Corticosteroid induced cutaneous atrophy and teleangiectasia. Arch Dermatol. 1976;112:1115-1117.

22. Krutmann JT, Morita A. Phototherapy for atopic dermatitis. In: Bieber T, Leung DYM editors. Atopic dermatitis. Marcel Dekker Inc., New York, Basel; 2002. p. 501-551.

23. Nordwig ST, Thomas AL. The treatment of atopic dermatitis with topical immunomodulators. Clin Dermatol. 2003;21:215-224.

24. Rustin MHA. The safety of tacrolimus ointment for the treatment of atopic dermatitis: a review. Br J Dermatol. 2007;157:861-873.

25. Nghiem P, Pearson G, Langley RG. Tacrolimus and pimecrolimus: for cleaver prokaryotes to inhibiting calcineurin and treating atopic dermatitis. J Am Acad Dermatol. 2002;46:228-241.

26. Kino T, Hatanaka H, Miglyata S, et al. FK-506, a novel immunosuppressant isolated from a Streptomyces. II. Immunosuppressive effest of FK-506 in vitro. J Antibiot. 1987;40:1256-1265.

27. Liu J, Albers MW, Wandless TJ, et al. Inhibition of T-cell signalling by immunophilin-ligand complexes correlates with loss of calcineurin phosphatase activity. Biochemistry. 1992;31:3896-3901.

28. Banerji SS, Parsons JN, Tocci MJ. The immunosuppressant FK-506 specifically inhibits mitogen-induced activation of the interleukin-2 promoter and the isolated enhancer elements NFIL-2A and NF-AT1. Mol Cell Biol. 1991;11:4074-4087.

29. Tocci MJ, Matkovich DA, Collier KA, et al. The immunosuppressant FK506 selectively inhibits expression of early T-cell activation genes. J Immunol. 1989;143:718-276.

30. Kapp A, Allen BR, Reitamo S. Atopic dermatitis management with tacrolimus ointment (Protopic). J Dermatolog Treat. 2003;14 Suppl:5-16.

31. Fleischer AB Jr. Treatment of atopic dermatitis: role of tacrolimus ointment as a topical noncorticosteroidal therapy. J Allergy Clin Immunol. 1999; 104:126-130. 
32. Kaye RE, Fruman DA, Bierer BE, et al. Effects of cyclosporine A and FK506 on Fc epsilon receptor type I-initiated increases in cytokine mRNA in mouse bone marrowderived progenitor mast cells: resistance to FK506 is associated with a deficiency in FK506-binding protein FKBP12. Proc Natl Acad Sci U S A. 1992;89:8542-8546.

33. Wollenberg A, Sharma S, von Bubnoff D, et al. Topical tacrolimus (FK506) leads to profound phenotypic and functional alterations of epidermal antigen-presenting dendritic cells in atopic dermatitis. J Allergy Clin Immunol. 2001;107:519-525.

34. Trautmann A, Akdis M, Schmid-Grendelmeier P, et al. Targeting keratinocyte apoptosis in the treatment of atopic dermatitis and allergic contact dermatitis. J Allergy Clin Immunol. 2001;108(5):839-846.

35. Neckermann G, Bavandi A, Meingassner JG. Atopic dermatitis-like symptoms in hypomagnesaemic hairless rats are prevented and inhibited by systemic or topical SDZ ASM 981. Br J Dermatol. 2000;142:669-679.

36. Sengoku T, Morita K, Sakuma S, et al. Possible inhibitory mechanism of FK506 (tacrolimus hydrate) ointment for atopic dermatitis based on animal models. Eur J Pharmacol. 1999;379:183-189.

37. Meingassner JG, di Padova F, Hiestand P, et al. Pimecrolimus (Elidel, SDZ ASM 981) in contrast to cyclosporin A and tacrolimus, is highly effective in animal models of skin inflammation but has only low activity in models indicating immunosuppressive potential. Pediatr Dermatol. 2001;18 Suppl:76.

38. Reitamo S, Van Leent EJM, Ho V, et al. Efficacy and safety of tacrolimus ointment compared with that of hydrocortisone acetate ointment in children with atopic dermatitis. J Allergy Clin Immunol. 2002;109:539-546.

39. Reitamo S, Remitz A, Kyllönen H, et al. Topical noncorticosteroid immunomodulation in the treatment of atopic dermatitis. Am J Clin Dermatol. 2002;3:381-388.

40. Reitamo S, Rustin M, Ruzicka T, et al. Efficacy and safety of tacrolimus ointment compared with that of hydrocortisone butyrate ointment in adult patients with atopic dermatitis. J Allergy Clin Immunol. 2002;109:547-555.

41. Reitamo S, Harper J, Bos JD, et al. 0.03\% tacrolimus ointment applied once or twice daily is more efficacious than $1 \%$ hydrocortisone acetate in children with moderate-to-severe atopic dermatitis: results of a randomized double-blind controlled trial. Br J Dermatol. 2004;150:554-562.

42. Pacor ML, Di Lorenzo G, Martinelli N, et al. Comparing tacrolimus ointment and oral cyclosporine in adult patients affected by atopic dermatitis: a randomized study. Clin Exp Allergy. 2004;34:639-645.

43. Kang S, Lucky AW, Pariser D, et al. Long-term safety and efficacy of tacrolimus ointment for the treatment of atopic dermatitis in children. J Am Acad Dermatol. 2001;44 Supp1 5:8-64.

44. Hanifin JM, Paller AS, Eichenfield L, et al. US Tacrolimus Ointment Study Group. Efficacy and safety of tacrolimus ointment treatment for up to 4 years in patients with atopic dermatitis. J Am Acad Dermatol. 2005;53 Suppl:186-194.

45. Remitz A, Harper J, Rustin M, et al. European Tacrolimus Ointment Study Group. Long term safety and efficacy of tacrolimus ointment for the treatment of atopic dermatitis in children. Acta Derm Venereol. 2007;87:54-61.

46. Reitamo S, Ortonne JP, Sand C, Cambazard F, et al. European Tacrolimus Ointment Study Group. A multicentre, randomized, double-blind, controlled study of long-term treatment with $0.1 \%$ tacrolimus ointment in adults with moderate-to-severe atopic dermatitis. $\mathrm{Br} J$ Dermatol. 2005;152:1282-1289.
47. Paller A, Eichenfield LF, Leung DY, et al. A 12-week study of tacrolimus ointment for the treatment of atopic dermatitis in pediatric patients. $\mathrm{J} \mathrm{Am}$ Acad Dermatol. 2001;44 Suppl:47-57.

48. Soter NA, Fleischer AB, Webster GF, et al. Tacrolimus Ointment Study Group. Tacrolimus ointment for the treatment of atopic dermatitis in adult patients: Part II. Safety. J Am Acad Dermatol. 2001;44:39-46.

49. Kang S, Lucky AW, Pariser D, et al. Long-term safety and efficacy of tacrolimus ointment for the treatment of atopic dermatitis in children. J Am Acad Dermatol. 2001;44 Suppl:58-64.

50. Baldo A, Casula L, Prizio E, et al. Topical tacrolimus and vitiligo: our experience in sixty cases. G Ital Dermatol Venereol. 2007;142:621-625.

51. Arellano FM, Wentworth CE, Arana A, et al. Risk for lymphoma following exposure to calcineurin inhibitors and topical steroids in patients with atopic dermatitis. J Invest Dermatol. 2007;127:808-816.

52. Fleisher AB, Ling M, Eichenfield L, et al. Tacrolimus ointment for the treatment of atopic dermatitis is not associated with an increase in cutaneous infections. J Am Acad Dermatol. 2002;47(4):562-570.

53. Callen J, Chamlin S, Eichenfield LF, et al. A systematic review of the safety of topical therapies for atopic dermatitis. $\mathrm{Br} J$ Dermatol. 2007; 156:203-221.

54. Harper J, Smith C, Rubins A, et al. A multicenter study of the pharmacokinetics of tacrolimus ointment after first and repeated application to children with atopic dermatitis. J Invest Dermatol. 2005;124(4):695-699.

55. Fujisawa. Summary of product characteristics. Protopic tacrolimus $0.003 \%$ and $0.1 \%$ ointment. April 2002.

56. Breuer K, Werfel T, Kapp A. Safety and efficacy of topical calcineurin inhibitors in the treatment of childhood atopic dermatitis. Am J Clin Dermatol. 2005;6:65-77.

57. Lawrence A, Lamerson C, Sheehan PM, et al. Tacrolimus ointment $0.03 \%$ is safe and effective for the treatment of mild to moderate atopic dermatitis in pediatric patients: results from a randomized, double-blind, vehicle-controlled study. Pediatrics. 2005;116(3):334-342.

58. Reitamo S, Rissanen J, Remitz A, et al. Tacrolimus ointment does not affect collagen synthesis: results of a single-center randomized trial. J Invest Dermatol. 1998;111:396-398.

59. Alaiti S, Kang S, Fiedler VC. Tacrolimus (FK506) ointment for atopic dermatitis: a phase I study in adults and children. J Am Acad Dermatol. 1998;38:69-76.

60. Pournaras CC, Lubbe J, Saurat JH. Staphylococcal colonization in atopic dermatitis treatment with topical tacrolimus (FK506). J Invest Dermatol. 2001;116:480-481.

61. Remitz A, Kyllonen H, Granlund H, et al. Tacrolimus ointment reduces staphylococcal colonization of atopic dermatitis lesions. J Allergy Clin Immunol. 2001;107:196-197.

62. Reitamo S. European Tacrolimus Ointment Study Group. 0.1\% Tacrolimus ointment is significantly more efficacious than a steroid regimen in adults with moderate to severe atopic dermatitis. 12th Congress of the European Accademy of Dermatology and Venereology, St Julian's, Malta. 27 February - 1 march. Poster presentation. p. 1-28.

63. Naylor M, Elmets CA, Rico MJ, et al. Treatment with topical tacrolimus is not associated with an increase in non-melanoma skin cancers. The American Academy of Dermatology 60th Annual Meeting. New Orleans, LA, USA. 22-27 February 2002:Poster presentation. p. 18.

64. Astellas Pharma GmbH. Summaries of Product Characteristics. Protopic 0.03\% Ointment. Mununich, Germany: Astellas Pharma GmbH 2006.

65. Baldo A, Prizio E, Mansueto G, et al. A case of chronic actinic dermatitis treated with topical tacrolimus. J Dermatolog Treat. 2005;16:245-248. 
